H A R V A R D

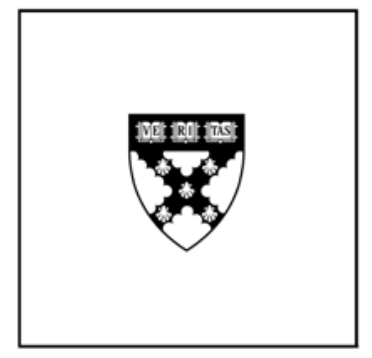

\title{
On the Descriptive Value of Loss Aversion in Decisions under Risk
}

\author{
Eyal Ert \\ Ido Erev
}

\section{Working Paper}

10-056 
On the Descriptive Value of Loss Aversion in Decisions under Risk

By Eyal Ert and Ido Erev

January 5, 2010

Contact information:

Eyal Ert, Computer Laboratory for Experimental Research, Harvard Business School, Boston, MA, 02163. Phone: 617-495-6753. email:eert@hbs.edu

Ido Erev, Faculty of Industrial Engineering and Management, Technion, Haifa, Israel, 32000. Phone: 972-829-4501. email: erev@tx.technion.ac.il 
On the Descriptive Value of Loss Aversion in Decisions under Risk

\begin{abstract}
Five studies are presented that explore the assertion that losses loom larger than gains. The first two studies reveal equal sensitivity to gains and losses. For example, half of the participants preferred the gamble " 1000 with probability 0.5 ; -1000 otherwise" over " 0 with certainty." Studies 3, 4, and 5 address the apparent discrepancy between these results and the evidence for loss aversion documented in previous research. The results reveal that only under very specific conditions does the pattern predicted by the loss aversion assertion emerge. This pattern does not emerge in short experiments or in the first 10 trials of long experiments. Nor does it emerge in long experiments with two-outcome symmetric gambles, or in long experiments with asymmetric multi-outcome gambles. The observed behavior, in these settings, reflects risk neutrality in choice among low-magnitude mixed gambles.
\end{abstract}

JEL Classification: C91, D01. 


\section{INTRODUCTION}

The loss aversion assertion, one of the assumptions that underlie prospect theory (Kahneman and Tversky (1979)), implies that losses loom larger than gains. That is, the absolute subjective value of a specific loss is larger than the absolute subjective value of an equivalent gain. This assertion was originally proposed in the context of decisions under risk: choice among known payoff distributions. It was later generalized to other settings, and was shown to provide an elegant explanation to a wide set of important behavioral phenomena. Famous examples are the endowment effect (Knetsch and Sinden (1984)), the status quo bias (Samuelson and Zeckhauser (1988)), and under-investment in the stock market (Benartzi and Thaler (1995)). The significance of loss aversion is highlighted in Camerer's (2000) review of the practical implications of prospect theory: seven of the ten examples are direct derivations of the loss aversion hypothesis.

However, recent research suggests that our understanding of the descriptive value and the implications of the loss aversion assertion is incomplete. One indication of this state is the suggestion of a chicken-and-egg relationship between loss aversion and some of the phenomena it has been brought to explain: While loss aversion is suggested to explain phenomena such as the status quo bias and the endowment effect, these phenomena are suggested as the evidence for the existence of loss aversion (Gal (2006)).

A second class of indications of our limited understanding of the descriptive value of the loss aversion assertion comes from studies of decisions from experience (see Hertwig et al. (2004)). Many of the phenomena explained by loss aversion involve situations in which the decision makers cannot rely on precise descriptions of the relevant payoff distributions. Rather, they have to rely on personal experience (e.g., Benartzi and Thaler (1995), Thaler et al. (1997), Camerer et al. (1997)). Thus, explaining these phenomena with loss aversion implies that loss aversion emerges in decisions from experience. In contradiction to this prediction, experimental studies of decisions from experience show no evidence of loss aversion. For example, in one of the studies summarized by Erev et al. (2008) participants had to make 100 choices between a gamble that offered equal probability of gaining or losing 1000 points and a safe option that ensured a payoff of 0 . The outcome of the chosen option was realized after each choice (and the points were converted to money at the end of the experiment). The results showed that the risky option was chosen in $50 \%$ of the trials; in contrast to the loss aversion prediction, the participants exhibited equal sensitivity to gains and losses. 
A final, and most important, class of indications of our limited understanding of the effect of losses on behavior comes from studies that support the loss aversion assertion in decisions under risk. An evaluation of these studies shows surprisingly few direct and simple tests of loss aversion. An early example of this state is provided by Kahneman and Tversky's (1979) seminal paper that introduced the loss aversion assertion. Prospect theory is designed to capture three main behavioral assertions: the certainty/possibility effect (overweighting of low probability outcomes), diminishing sensitivity (risk aversion in the gain domain and risk seeking in the loss domain), and loss aversion. The first two assertions are described before the presentation of the theory, and are motivated with simple experiments. The third assertion, loss aversion, is added during the presentation of the theory, and is not supported by experimental data. Kahneman and Tversky note that "...most people find symmetrical bets of the form (x, .50; -x, .50) distinctly unattractive" (Kahneman and Tversky (1979) p. 279), but none of their experimental problems include bets that involve both gains and losses (hereafter referred to as "mixed gambles").

Many follow-up studies have demonstrated that the loss aversion assertion can be used to predict, and/or to provide sufficient explanation to, interesting experimental results. Yet, most studies fall short from showing the advantage of the loss aversion assertion over likely alternative explanations. One important example is provided by studies that focus on variants of Samuelson's colleague problem (Samuelson (1963), and see Tversky and Redelmeier (1992), Kahneman (2003), Fehr and Goette (2007), Johnson et al. (2007), Tom et al. (2007), McGraw et al. (2009)). In a representative study Tversky and Redelmeier asked their participants whether they would accept a gamble that offers an equal chance of gaining \$2000 or losing $\$ 500$. The results revealed that the majority of people (56\%) rejected this attractive (expected value wise) gamble. The loss aversion assertion provides a sufficient explanation to this preference: The typical participant, under this explanation, behaves as if a loss of $\$ 500$ looms larger than a gain of $\$ 2000$. Yet another likely explanation of this result is provided by the status quo bias. It is possible that the high rejection rate is a result of the mere fact that rejecting the gamble (the safer decision) is framed as the status quo. Recent research demonstrates an interesting advantage of the status quo explanation over loss aversion. In one study (Ert and Erev (2008)) only 55\% of the participants were willing to accept the attractive gamble under Tversky and Redelmeier's “would you play a gamble” format, but $78 \%$ of the participants preferred that gamble when the status quo framing was avoided. That is, $78 \%$ preferred the prospect " $\$ 2000$ with probability $0.5,-\$ 500$ otherwise" over the prospect " 0 with certainty." 
Other studies examined loss aversion using variants of the certainty equivalence procedure (e.g., Shoemaker (1990), Tverksy and Kahneman (1992), Bleichrodt et al. (2001), Schmidt and Traub (2002)), or the probability equivalence procedure (e.g., Williams (1966)). The results of these studies are consistent with the prediction of a strong loss aversion bias, but they could also be explained by the context effect (see Garner (1954), Birnbaum (2008), Erev, Glozman, and Hertwig (2008)). Another class of studies (e.g., Payne et al. (1980), Payne et al. (1981), Thaler et al. (1997)) focuses on choice among mixed gambles with positive expected values. The results support the loss aversion predictions, but can also be explained as a product of diminishing sensitivity relative to the reference point (a robust feature of prospect theory). Erev, Ert, and Yehicam (2008) show the advantage of the diminishing sensitivity explanation. Finally, several studies examine loss aversion in choices among high stake (hypothetical) gambles (e.g., Abdellaoui et al. (2007, 2008)). The results are consistent with loss aversion, but could not be differentiated from mere risk aversion which is typically observed in decisions that involve high stakes (see Holt and Laury (2002)).

The current paper tries to improve our understanding of the descriptive value of the loss aversion assertion by focusing on choices among low magnitude prospects that involve similar gains and losses. This setting minimizes the risk of confounding the effect of loss aversion with the known effects listed above. The paper starts with two direct tests of loss aversion. Study 1 uses Kahneman and Tversky's experimental paradigm to test the unique implications of loss aversion. The results show no evidence for loss aversion: Only $50 \%$ of the participants prefer " 0 with certainty" over " 1000 with probability $0.5 ;-1000$ otherwise." Study 2 demonstrates the robustness of Study 1's results in choice among gambles that are played for real money.

The analysis continues by evaluating the apparent discrepancy between the current results and recent research that support loss aversion in choice among small magnitude mixed lotteries (e.g., Brooks and Zank (2005)). A re-analysis of previous studies, supported by the results of Study 3, suggest that part of this discrepancy is driven by an order effect: Participants do not exhibit loss aversion in short studies, or at the beginning of long studies but, in certain settings, they act as if they become loss averse with time. Studies 4 and 5 show two important boundaries to this order effect. It does not emerge when the possible prospects involve two, equally likely, outcomes (Study 4), and it does not emerge in choice among multi-outcome gambles (Study 5). The observed choices, in these settings, reflect equal weighting of gains and losses. 


\section{DIRECT EXPERIMENTAL TESTS OF LOSS AVERSION}

\section{Study 1 - Hypothetical Payoffs}

Study 1 examines loss aversion under Kahneman and Tversky (1979) hypothetical payoffs paradigm. It focuses on the following four problems:

Problem Mixed 1 S 0 with certainty

$$
\begin{array}{ll}
\text { R } 1000 \text { with probability } 0.5 & P(R)=0.50 \\
-1000 \text { otherwise } &
\end{array}
$$

Problem Gain $1 \quad$ S 1000 with certainty

$$
\begin{aligned}
& \text { R } 2000 \text { with probability } 0.5 \quad \mathrm{P}(\mathrm{R})=0.24 \\
& 0 \text { otherwise }
\end{aligned}
$$

Problem Mixed 2 S 1000 with probability 0.5

-1000 otherwise

$\begin{array}{ll}\text { R } 4000 \text { with probability } 0.5 & \mathrm{P}(\mathrm{R})=0.37\end{array}$

-4000 otherwise

Problem Gain $2 \quad$ S 5000 with probability 0.5

3000 otherwise

R 8000 with probability $0.5 \quad \mathrm{P}(\mathrm{R})=0.13$

0 otherwise

The hypothetical outcomes represent payoffs in Sheqels where $\$ 1=4.2$ Sheqels. The $P(R)$ values presented on the right summarize the main results and will be discussed in the results section below. Note that Problem Gain 1 was created by adding 1000 to all of the payoffs in Problem Mixed 1 and Problem Gain 2 was created by adding 4000 to all of the payoffs in Problem Mixed 2. This was done to evaluate Thaler et al.'s (1997, page 651) statement that loss aversion implies higher risk aversion in the mixed domain than in the gain domain. 
Experimental Design - The four problems were presented in a short one-page questionnaire. Seventy Students at the Technion were asked to circle the prospect they preferred in each of the problems. ${ }^{1}$ The order of the four problems was balanced over participants.

Results - The choice rates of the risky options (R-rates) are presented to the right of the four problems. The results reveal a clear violation of Thaler et al.'s (1997) hypothesis that risk aversion is strongest in choices among mixed prospects. Indeed, a significant reversal of this prediction was documented. The observed R-rates in the mixed problems (50\% and 37\%) were higher than the observed R-rates in the gain problems (24\% and $13 \%)$. This reversed loss aversion pattern is significant $(t(69)=3.09, p<.003 ; t(69)=3.89, p<.0003$; for the differences in the first and second pairs, respectively).

In addition, the results reveal a higher R-rate in Problem Mixed 1 and Problem Gain 1 (50\% and 24\%) than in Problem Mixed 2 and Problem Gain 2 (37\% and 13\%). This difference is consistent with the assertion that payoff magnitude increases risk aversion (see Holt and Laury (2002)). The rest of the paper will avoid this issue by focusing on lower stakes.

\section{Study 2 - Low Stakes, Real Payoffs}

The second study is designed to evaluate the robustness of the results of Study 1 to the experimental paradigm. Specifically, it focuses on decisions for real money by using a variant of Problems Mixed 2 and Gain 2 as follows (the outcomes represent payoffs in Sheqels):

Problem S 10 with probability 0.5

Mixed $3 \quad-10$ otherwise

R 20 with probability 0.5 $\mathrm{P}(\mathrm{R})=0.58$

-20 otherwise

Problem S $\quad 30$ with probability 0.5

Gain $3 \quad 10$ otherwise

\footnotetext{
${ }^{1}$ Thirty-four of the students were asked to answer the questionnaire during the first class of the course "Decision Making." The remaining participants were asked to fill the experimental questionnaire after they completed an experiment on social choice (a replication of Charness and Grosskopf (2001)). There was no significant difference between these two groups' responses.
} 
R 40 with probability 0.5
0 otherwise

Experimental Design - Seventy-two Technion students served as paid participants in this study. The participants sat in front of personal computers and were presented with each of the two problems shown above. In each problem, participants were asked to mark the prospect they preferred to play. The order of the problems was balanced over participants. At the end of the experiment one problem was randomly selected, and its payoff was realized according to the participants' choice in that problem.

In order to facilitate the generation of real losses, participants were recruited for two experiments: the one that is reported here, and a filler (unrelated) experiment. The earnings from the filler experiment were between 20 and 32 Sheqels. The order of the experiments was counterbalanced. Participants were told that in case they lose money in the target experiment, their loss would be subtracted from their earnings in the filler experiment. We followed Holt and Laury's (2002) suggestion to let participants "work" for the money, rather than giving them endowment, to decrease the possibility of "house money" effects (Thaler and Johnson (1990)). ${ }^{2}$ Final payoffs of the target experiment ranged between a loss of 20 Sheqels and a win of 40 Sheqels $(-\$ 5$ and $+\$ 10)$.

Results - The choice rates of the risky options are presented to the right of the two problems. The results replicate the pattern observed in Study 1. Again, the proportions of risky choices were much higher in the mixed problem $(0.58)$ than in the gain domain $(0.31){ }^{3}$ This reversal of the prediction made by Thaler et al. (1997) is significant $(t(71)=3.6, p<.001)$ and the similarity of the current results to those observed in Study 1 suggests that this pattern is robust to decisions with real (small stakes) incentives. The high proportion of risky choices in the mixed domain also rejects Kahneman and Tversky's (1979) hypothesis: participants were not risk averse while choosing between mixed gambles with real (though relatively low) stakes.

\footnotetext{
${ }^{2}$ In the following studies $(3,4$, and 5$)$ we also followed the convention of most mixed-gambles studies that endow participants with money at the beginning of the experiment (e.g., Battalio, Kagel, and Jiranyakul (1990), Brooks and Zank (2005), Harless (1992)). We have not observed any difference in behavior between these two methods.

${ }^{3}$ We also checked for possible order effects: neither the ordering of the two problems, nor the ordering of the two experiments had an effect on the current results. In all four orders the proportion of risky choice in Problem Mixed 3 was extensively higher than in Problem Gain 3. It is also worth noting that the proportion of risk taking in Condition Mixed 3 is not significantly different than $50 \%(t(71)=1.42$, NS $)$.
} 


\section{EVALUATING THE APPERENT DisCREPENCY BETWEEN THE CURRENT AND PREVIOUS STUDIES OF LOSS AVERSION}

Study 3 - The order effect: Loss aversion develops with time in certain long studies

Table I compares the results of Study 1 and 2 with the results obtained in several previous studies that used a similar method (and minimized the expected effect of the status quo framing, the context effect, diminishing sensitivity, and risk aversion). It highlights two main differences between the studies that do not find loss aversion and the studies that support the loss aversion assertion. One difference relates to the length of the study and the other one is associated with the computational difficulty of the prospects' expected values. The studies that did not find loss aversion tended to be short (like Studies 1 and 2 that include 4 and 2 problems respectively), and to focus on gambles with two equally likely outcomes. In contrast, the studies that support the loss aversion hypothesis included many choice problems between prospects with asymmetric probabilities (i.e., different probabilities for gains between prospects and different probabilities of gains and losses within each prospect).

\section{$<$ Insert Table I $>$}

Figure 1 clarifies the suggested role of the length of the experiment in risk taking. It presents the proportion of risky choices in decisions among mixed gambles as a function of the experimental trial in three different studies. The results reveal a similar order effect in all three studies: the tendency to select the risky prospect deceases with time. This pattern is consistent with the assertion that repeated choices without feedback facilitate loss aversion.

Study 3 was designed to evaluate the robustness of this order effect. It focuses on choice among two outcomes mixed gambles in 90 problems.

\section{$<$ Insert Figure 1 >}

Experimental Design - Thirty Technion students participated in the current study. Each participant was seated in front of a personal computer and was then presented with 90 problems that involved choice between two mixed gambles with similar expected values (see Table II). The order of the problems was randomized across participants. At the end of the experiment one of the problems was randomly selected to determine the participant's payoff. Final payoffs ranged between 12 and 48 Sheqels (about $\$ 3$ and $\$ 12$, respectively). 
$<$ Insert Table II $>$

Results - The choice proportions of the riskier prospects are presented in Table II. The choice rate of the risky prospect was $41 \%$ over the 90 problems. This proportion is significantly lower than $50 \%(\mathrm{t}(29)=-2.31, \mathrm{p}<0.03)$, the rate of risk taking predicted under equal weighting of gains and losses. The estimated value of the loss aversion parameter under the Cumulative Prospect Theory model (CPT) is $\lambda=1.6$ (See Appendix A.1). This parameter implies higher weighting of losses than gains.

The gray line in Figure 2 presents the proportion of risky choices as a function of the experimental trial. The results show that the participants started the experiment by exhibiting near indifference between the safer and riskier prospects. The results replicate the pattern documented in Figure 1: The tendency to select the risky prospect decreased with the trial number $(t(29)=3.13, p<.005$, for the difference in risk taking between the first 10 problems and the rest of the problems).

$<$ Insert Figure 2 $>$

Study 4 - Potential accounts for the order effect: Initial confusion or resource depletion?

Study 4 was designed to compare two potential explanations of the order effect documented above. The first explanation suggests that the results of the short studies, and the results of the first few trials in the long studies, reflect misunderstanding of the task. Thus, the choice rates in the later stages of the long studies reflect the "true preferences." This "initial confusion" hypothesis implies that the "true preferences" reflect loss aversion.

According to an alternative explanation, the order effect might reflect resource depletion (Pocheptsova et al. (2009)). The studies in which the order effect was observed included choice between asymmetric prospects with similar expected values, so the attempt to select the "right" option requires cognitive effort. Previous research has suggested that cognitive processing in decision making draws on a limited source required for executive control (e.g., Schmeichel (2007), Vohs et al. (2008)). Thus, making long series of choices or being engaged in effortful tradeoff comparisons might facilitate reliance on simple effort minimizing rules. According to this explanation the reduced risk taking across time reflects resource depletion rather than "true preferences."

In order to evaluate the two explanations we studied choice behavior in a new set of 90 mixed problems presented in Table III. This set is similar to the set used in Study 3 in that 
it includes choice between two-outcome mixed gambles. However, the current, "symmetric," set only involves choices among prospects with two equally likely outcomes, while Study 3's focused on an "asymmetric" set of mixed gambles that included outcomes with different probabilities of occurrence. The problems were counterbalanced in terms of the expected values (EV) associated with the different alternatives. In 40 of the problems the riskier gamble was associated with the higher EV, in another 40 of the problems the safer gamble was associated with the higher EV, and in 10 of the problems both alternatives had the same EV.

Assuming that choice in the asymmetric set that was studied in Study 3 requires more difficult computations (and stronger resource depletion), the two hypotheses predict different order effects in the two sets. The initial confusion hypothesis predicts a decrease in risky choices with order in the two sets. The resource depletion hypothesis predicts much weaker decrease in the current set.

$<$ Insert Table III $>$

Experimental Design - Twenty-two students participated in the current study. Each participant was seated in front of a personal computer and was then presented with the 90 problems. The problems involved choice between two mixed gambles with similar expected values. The order of the problems was randomized across participants. At the end of the experiment one of the problems was randomly selected to determine the participant's final payoff. Final payoffs ranged between 9 and 48 Sheqels ( $\$ 2.25$ and $\$ 12$, respectively).

Results - The choice proportions of the riskier prospects are presented in Table III. The choice rate of the risky prospect was $48 \%$ over the 90 problems, and $51 \%$ in the 10 problems with equal expected values. Neither rate is significantly different than $50 \%$. The estimated value of the loss aversion parameter under the Cumulative Prospect Theory model (CPT) is $\lambda$ $=1$ (see Appendix A.2). This parameter implies equal weighting for gains and losses.

The black line in Figure 3 represents the proportion of risky choices as a function of the experimental trial. The results show that the participants start the experiment by exhibiting near indifference between the safer and riskier prospects, and this tendency does not change much with the course of the experiment. Additional analysis reveals that the choice rate of the higher EV prospect (in the 80 problems with unequal EV) was $79 \%$. 
The results support the resource depletion hypothesis and contradict the "initial confusion" hypothesis. The symmetric simplification of the choice task (in an attempt to reduce confusion and cognitive depletion) eliminated the evidence for loss aversion.

\section{Study 5 - Multiple outcome gambles}

Study 5 was designed to compare two interpretations of the depletion effect suggested above. Under one interpretation this effect reflects a general relationship between depletion (that emerges after several difficult and/or annoying computations) and loss aversion: Depletion always triggers loss aversion. A second interpretation assumes that the effect is less general. Only when the behavior predicted by loss aversion is implied by an easy rule that was found to be useful in similar past experiences does it emerge (see related ideas in Payne, Bettman, and Johnson (1993), and Brandstätter, Gigerenzer, and Hertwig (2006)). One example of an "easy rule" that can capture the main results presented above states: "Select the prospect that maximizes the probability of gain and maximizes the worst payoff (and think again if you cannot find a prospect that achieves both goals)." Notice that the potential value of this rule is situation specific; it is not useful (implies "think again") when probabilities are equal and neither prospect achieves both goals (as in Studies 1, 2, and 4), but it is useful in half of the problems in Study 3. The proportion of choices consistent with this rule, over the 45 pairs in which it has clear prescriptions, is 67\% (and the proportion of problems in which most subjects behave in accordance with this rule is 93\%). Other easy rules are likely to be triggered in different settings, and the results of Study 4 suggest that they do not have to imply loss aversion. Indeed, the results of Study 4 are best described with the rule "select the option with the highest expected value." This rule is easy to use in 80 of the problems in Study 4, and it captures $79 \%$ of these choices (and the proportion of problems in which most subjects behave in accordance with this rule is $100 \%$ ).

In order to compare these interpretations of the depletion hypothesis we chose to consider choice among the multi-outcomes problems described in Table IV. ${ }^{4}$ The computation of the expected values in these tasks is very difficult. Thus, if computation difficulty always triggers loss aversion, we should observe a strong tendency to select the safer prospect. At the same time, it is hard to find an easy rule that simplifies the current choice task and implies loss aversion-like behavior. In particular, derivation of the rule

\footnotetext{
4 The 40 basic prospects were randomly selected from a space of prospects that satisfies two main constraints: round payoffs in the range between -10 to +10 , and a payoff distribution with up to 7 modes.
} 
considered above, "select the prospect that maximizes probability of gain and maximizes the worst payoff," is not easy (it requires the discovery of the worst payoffs and the summing up of many small probabilities). That is, the "easy rule" interpretation of the depletion hypothesis does not have clear prediction in this setting.

Experimental Design - Thirty students participated in this study. Each participant was faced with 80 problems: the 40 problems presented in Table IV, and a reflection of each of those problems (the reflections were created by multiplying each payoff by -1 ). The problems were described to the subjects with a list of the possible outcomes and their probabilities. The location of the different outcomes in the list was randomly determined (Figure 3 presents one example).

$$
<\text { Insert Figure 3 }>
$$

The ordering of each set of 40 problems (the basic and the reflected problems) was counterbalanced. The ordering within each set was randomized. At the end of the study one problem was randomly selected and the participant was compensated according to his or her choice and the realization of the selected prospect. Final payoffs ranged between 28 and 39 Sheqels (\$7 and respectively \$9.8).

\section{$<$ Insert Table IV $>$}

Results - The proportion of risk taking in each of the problems is presented in Table IV. The proportion of risk taking across problems is $49 \%$. The small difference from $50 \%$, the rate predicted under equal weighting of gains and losses, is insignificant $(t(29)=-0.8$, NS).

A similar picture emerges from an estimation of the parameters of cumulative prospect theory (see Appendix A.3). The estimated loss aversion parameter $(\lambda=1)$ implies equal weighting of gains and losses.

Additional analyses reveal that in both conditions, most choices (72\%) were consistent with expected value maximization. In addition, $74 \%$ of the choices were consistent with extreme diminishing sensitivity (maximization of the expected subjective value under a step function that assigns the value +1 to all gains, 0 to the payoff 0 , and the value -1 to all losses). Notice that extreme diminishing sensitivity is a generalization of the "minimizing probability of losses rule" discussed above. 
These results contradict the assertion that computation difficulty (or the implied cognitive depletion) always triggers loss aversion. Rather, it seems that the effect of computational difficulty depends on the availability of an easy and reasonable choice rule that implies the behavior predicted by the loss aversion hypothesis.

\section{DISCUSSION AND CONCLUSIONS}

The current results suggest that the effect of losses on decisions under risk is more complex than the effect assumed in prospect theory. It is not always true that losses loom larger than gains. About half of our participants preferred gambles that provide "equal chances to win or lose $x$ " over safer prospects with the same expected value. These results reveal no evidence for loss aversion; they imply risk neutrality in choice among symmetric two-outcome mixed gambles. A similar pattern was documented in choices among asymmetric multi-outcome gambles, and in the initial choices among asymmetric twooutcome gambles.

\section{Relationship to the Popular Applications of Loss Aversion}

The significance of the current results could be questioned on the ground that our experimental paradigm focuses on trivial decisions in an abstract setting. Much of the support for loss aversion, in contrast, was documented in more natural settings and in the analysis of more consequential decisions. Thus, it is possible that the current results reflect an isolated and artificial counterexample to loss aversion (see a related discussion in Samuelson 2005).

In order to evaluate this critique we chose to reconsider three of the best-known natural phenomena that have been explained with the loss aversion assertion. Specifically, we focus on the status quo bias (Samuelson and Zeckhauser (1988)), the endowment effect (Knetsch and Sinden (1984)), and underinvestment in stocks (Benartzi and Thaler (1995)). All three phenomena appear to be more important and interesting than the phenomenon documented above (risk neutrality in choice among low magnitude mixed gambles). Yet, two observations suggest that the existence of these interesting phenomena does not eliminate the potential importance of the current results. The first observation involves the fact that the loss aversion is only one of many feasible explanations of these phenomena. Examples of nonloss-aversion explanations that have been proposed in previous research are presented below each of the phenomena in the left hand side of Table V. 
A second, and more important, observation involves the generality of the trend suggested by the phenomena explained by loss aversion. The right hand side of Table V lists examples of natural phenomena that appear to reflect reversals of the "loss aversion" phenomena. The first row compares the status quo bias with "overtrading in the stock market." The term "overtrading" captures the fact that people tend to trade more than predicted under the rational model; overtrading appears to reflect a reversal of the status quo bias. Thus, under the assumption that the status quo bias is a reflection of loss aversion, overtrading might be described as a reflection of a reversed loss aversion bias.

The second row compares the endowment effect with "overbidding in auctions" (see a recent review by Kagel and Levin (2008)). The endowment effect implies that potential buyers undervalue products that they do not own while overbidding implies the opposite.

Finally, the lower row in Table V compares "under investment in the stock market" with "insufficient diversification" (see Barber and Odean (2000), Polkovnichenko (2005)). Thaler and Benarzi (1995) show that under investment implies extreme risk-aversion in choice among mixed prospects, and it is naturally captured with a variant of prospect theory that assumes myopic loss aversion. Insufficient diversification (e.g., the tendency to prefer individual stocks over index funds, see Barber and Odean (2000)) implies risk seeking in choice among mixed prospects. Thus, if underinvestment reflects loss aversion, insufficient diversification appears to reflect a reversed loss aversion bias.

In summary, Table $\mathrm{V}$ suggests that the evidence for a general loss aversion bias in natural settings is mixed. Whereas most previous attempts to relate the loss aversion assertion to field research focused on phenomena that can be explained as reflections of loss aversion, it is easy to think of phenomena that can be explained with the opposite bias. Namely, it is possible that the current results reflect more than an isolated counterexample for loss aversion.

\section{$\underline{\text { Two Feasible Abstractions }}$}

It is constructive to distinguish between two classes of feasible abstractions of the distinct effects of losses described above. The first class includes generalizations of expected utility theory. These models share the assumption that choice behavior is a product of a weighting of the utility (subjective value) of the possible outcomes by their subjective probabilities. Cumulative prospect theory is a member of this class (see Wakker (2009)). 
Implicit in the common interpretations of these models is the assumption that the participants in experiments that focus on decisions from description (like the current experiments) treat the descriptions of the possible payoffs and their probabilities as the "objective payoff distributions." Thus, their deviation from expected value maximization is a reflection of the fact that the subjective values and the subjective probabilities differ from the objective payoffs and their probabilities. The different members of this class differ with respect to the assumed subjective functions. The current results can be captured with these generalizations of expected utility theory with the assumption that the exact parameters that determine the subjective values are situation specific. For example, the results can be captured with cumulative prospect theory with the assertion that the "loss aversion" parameter is close to 1 (implies equal sensitivity to gains and losses) in Experiments 1, 2, 4, and 5, and is larger than 1 (implies that losses loom larger than gains) in Experiment 3. Under another interesting "prospect theory based abstraction" the loss aversion parameter is constant over tasks, but the reference point parameter changes between tasks, and between individuals. For instance, it can be a reflection of subjective expectations (see related ideas in Koszegi and Rabin (2006), Novemsky and Kahneman (2005)). Such an abstraction can capture the risk neutrality observed in Experiments 1, 2, 4, and 5 with the assumption that about half the decisionmakers set the worst possible payoff as their reference point (e.g., -1000 in Problem 1), and the other half set their reference point at the best possible payoff (e.g., +1000 in Problem 1).

A second class of abstractions includes case-based decision models (see Gilboa and Schmeidler (1995)). These models share the assumption that the decision-makers weigh experiences and tend to select easy strategies that have led to the best outcomes in similar cases in the past. Case-based models allow for the possibility that the decision-makers do not treat the description of the incentive structure at face value. Rather, the description can be treated as a cue to retrieve relevant experiences (cases) from memory. For an extreme example, consider SPAM email messages. Many of these messages offer deals that seem too good to be true (e.g., consider an e-mail message retrieved from the first author's junk mail folder: "Are you interested in discovering a secret way of making a fortune with foreclosures...without having to buy or sell the houses?! Then join Mike on this very special training session on how to: Make $\$ 12,817$ in 30 days or less starting with only $\$ 1$. Go to the link below and get all the juicy details..."). It seems natural to assume that our experience in a world with many "markets for lemons" (Akerlof (1970)) has taught us that the true incentive structure can differ from the described incentive structure. 
The results presented above cannot be used to decisively compare these two feasible classes of abstractions. Nevertheless, we feel that they highlight the potential of the casebased approach. One indication of this potential is highlighted by the "easy rule" interpretation of the depletion hypothesis discussed above. A second indication is related to the role of unobservable variables. As noted by Pasendorfer (2006), one of the most important shortcomings of leading experimental-based models of economic behavior is the reliance on unobservable variables like prospect theory's reference point that cannot be easily estimated outside the laboratory. ${ }^{5}$ It seems that the similarity concept used by the case-based approach can address this important critique. A third, and perhaps more interesting, indication of the potential of this approach involves the comparison between the two sides of Table $\mathrm{V}$. The phenomena on the left (the phenomena that have been associated with loss aversion) appear to emerge in environments that seem similar to markets for lemons. The typical behavior can be described as a tendency to reject attractive offers from agents that know more than the decision-maker (see Dupont and Lee (2002) for a similar argument). The phenomena on the right (that could be referred to as "reversed loss aversion phenomena"), on the other hand, seem to be associated with an environment that is more similar to competitive settings. In many of these settings the agents can win or lose, and have to take some risk in order to win.

Notice that the current speculation implies a reversal of the common "hand waving" concerning the relationship between individual decisions under risk and behavior in games. Mainstream research use concepts from the study of decisions under risk (like the loss aversion assertion) to explain behavior in games. The current speculation suggests the opposite: We assert that behavioral tendencies that were evolved in common games might drive decisions under risk. We hope that the current clarification of the basic phenomena will help to advance future theoretical analyses beyond the hand waving stage.

\section{$\underline{\text { Summary }}$}

Losses appear to loom larger than gains in some environments, but not in others. The current results reveal no evidence for loss aversion in choice among symmetric twooutcome mixed gambles. A similar pattern was documented in choices among asymmetric multi-outcome gambles, and in the initial choices among asymmetric two-outcome gambles. These and similar results can be captured with the assertion that the exact effect of losses is

\footnotetext{
${ }^{5}$ In fact, even inside the lab estimating potential reference point is sometimes not trivial. For example, a reference risk might pertain to payoffs, but also to probabilities (see Viscusi, Magat, and Huber 1987).
} 
not a result of a stable value function; rather, the effect of losses might depend on the similarity of the current decision environment to past experiences. 


\section{REFERENCES}

Abdellaoui, Mohammed, Han bleichrodt, and Corina Paraschiv (2007): "Loss Aversion under Prospect Theory: A Parameter-Free Measurement," Management Science, 53, 1659-1674. Abdellaoui, Mohammed, Han bleichrodt, and Olivier L. Haridon (2008): “A Tractable Method to Measure Utility and Loss Aversion under Prospect Theory,"Journal of Risk and Uncertainty, 36, 245-266.

Aiyagari, Rao S., and Mark Gertler (1991): “Asset Returns with Transactions Costs and Uninsured Individual Risk,” Journal of Monetary Economics, 27, 311-31.

Akerlof, George A. (1970): “The Market for "Lemons:” Quality Uncertainty and the Market Mechanism," Quarterly Journal of Economics, 84, 488-500.

Barber, Brad M., and Terrance Odean (2000): "Trading is hazardous to your wealth: The common stock investment performance of individual investors,” Journal of Finance, 55, 773-806.

Battalio, Raymond C., John. H. Kagel, and Komain Jiranyakul (1990): “Testing Between Alternative Models of Choice under Uncertainty: Some Initial Results,” Journal of Risk and Uncertainty, 3, 25-50.

Bazerman, Max H., and William, F. Samuelson (1983): “I won the Auction but Don't Want the Prize," Journal of Conflict Resolution, 27, 618-634.

Benartzi, Shlomo, and Richard H., Thaler (1995): "Myopic Loss Aversion and the Equity Premium Puzzle," Quarterly Journal of Economics, 110, 73-92.

Birnbaum, Michael H. (2008): "New Paradoxes of Risky Decision Making," Psychological Review, 115, 463-501.

Bleichrodt Han, Jose L. Pinto, and Peter P. Wakker (2001): "Making Descriptive Use of Prospect Theory to Improve the Prescriptive Use of Expected Utility," Management Science, 47, 1498-1514.

Brandstätter, Edward, Gerd Gigerenzer, and Ralph Hertwig (2006): “The Priority Heuristic: Making Choices without Tradeoffs," Psychological Review, 113, 409-432.

Brooks Peter, and Horst Zank (2005): “Loss Averse Behavior,” Journal of Risk and Uncertainty, 31, 301-325.

Camerer, Colin F., "Prospect Theory in the Wild: Evidence from the Field," In Choices, Values, and Frames. D. Kahneman and A. Tversky, eds. (Cambridge, U.K: Cambridge, University Press, 2000). 
Camerer, Colin F., Linda Babcock, George Lowenstein, and Richard Thaler (1997): "Labor Supply of New York Cab Drivers: One Day at a Time," Quarterly Journal of Economics, $112,407-441$.

Charness, Gary, and Brit Grosskopf (2001): "Relative Payoffs and Happiness: An Experimental Study," Journal of Economic Behavior and Organization, 45, 301-328.

Constantinides, George M. (1990): "Habit Formation: A Resolution of the Equity Premium Puzzle," Journal of Political Economy, 98, 519-543.

Constantinides, George M., John, Donaldson, and Rajnish Mehra (2002): “Juniors Can't Borrow: A New Perspective on the Equity Premium Puzzle," Quarterly Journal of Economics, 117, 269-296.

Dupont, Dominique Y., and Gabriel S. Lee (2002): “The Endowment Effect, Status Quo Bias and Loss Aversion: Rational Alternative Explanation," Journal of Risk and Uncertainty, $25,87-101$.

Erev, Ido, Eyal Ert, and Eldad Yechiam (2008): "Loss Aversion, Diminishing Sensitivity, and the Effect of Experience on Repeated Decisions," Journal of Behavioral Decision Making, 21, 575-597.

Erev, Ido, Eyal Ert, Alvin E. Roth, Ernan Haruvy, Stefan Herzog, Robin Hau, Ralph Hertwig, Terrence Stewart, and Christian Lebiere (2010): “A Choice Prediction Competition: Choices from Experience and from Description,” Journal of Behavioral Decision Making, $23,15-47$.

Ert, Eyal, and Ido Erev (2008): "The Rejection of Attractive Gambles, Loss Aversion, and the Lemon Avoidance Heuristic,” Journal of Economic Psychology, 29, 715-723.

Ert, Eyal, and Eldad Yechiam (2009): "Toward the Building Blocks of Risk Taking: An Examination of Consistent Constructs in Individual's Decisions," Technion Working paper.

Fehr, Ernst, and Lorenze Goette (2007): "Do Workers Work More if Wages Are High? Evidence from a Randomized Field Experiment," American Economic Review, 97, 298317.

Gal, David (2006): “A psychological Law of Inertia and the Illusion of Loss Aversion,” Judgment and Decision Making, 1, 23-32.

Garner, Wendell R. (1954): “Context Effects and the Validity of Loudness Scales,” Journal of Experimental Psychology, 48, 218-224.

Gilboa, Itzhak., and David Schmeidler (1995): “Case-Based Decision Theory,” Quarterly Journal of Economics, 30, 605-639. 
Harless, David W. (1992): "Predictions about Indifference Curves Inside the Unit Triangle: A Test of Variants of Expected Utility Theory," Journal of Economic Behavior and Organization, 18, 391-414.

Hertwig, Ralph, Greg Barron, Elke U. Weber, and Ido Erev (2002): “Decisions from Experience and the Effect of Rare Events in Risky Choice," Psychological Science, 15 (2004), 534-539.

Holt, Charles A., and Susan K. Laury (2002): "Risk Aversion and Incentive Effects," American Economic Review, 92, 1644-1655.

Johnson, Eric J., Simon Gachter, and Andreas Herrman (2007): "Exploring the Nature of Loss aversion,” IZA Discussion Paper No. 2015.

Kagel, John H., and Dan Levin (forthcoming): “Auctions: A Survey of Experimental Research, 1995-2008," in Handbook of Experimental Economics, Vol. 2, J. H. Kagel and A. E. Roth eds. (Princeton University Press).

Kahneman, Daniel (2003): "Maps of Bounded Rationality: Psychology for Behavioral Economics," American Economic Review, 93, 1449-1575.

Kahneman, Daniel, and Amos Tversky (1979): "Prospect Theory: An Analysis of Decision under Risk," Econometrica, 47, 263-291.

Novemsky, Nathan, and Daniel Kahneman (2005): “The Boundaries of Loss Aversion," Journal of Marketing Research, 42, 119-128.

Knetsch, Jack L., and J. A. Sinden (1984): "Willingness to Pay and Compensation Demanded: Experimental Evidence of an Unexpected Disparity in Measures of Value," Quarterly Journal of Economics, 99, 507-521.

Koszegi, Botond, and Matthew Rabin (2006): “A Model of Reference Dependent Preferences," Quarterly Journal of Economics, 121, 1133-1166.

McKenzie, Craig R. M., Michael J. Liersch, and Stacey. R. Finkelstein (2006):

“Recommendations Implicit in Policy Defaults,” Psychological Science, 17, 414-420.

Mehra, Rajnish, and Edward Prescott (1985): “The Equity Premium: A Puzzle,” Journal of Monetary Economics, 15, 145-161.

McGraw, Peter A., Jeffrey T. Larsen, Daniel Kahneman, and David Schkade (2009): “Do Bipolar Scales Mask Loss Aversion?” Working Paper, University of Colorado.

Morewedge, Carey M., Lisa L. Shu, Daniel T. Gilbert, and Timothy D. Wilson (2009): "Bad riddance or good rubbish? Ownership and not loss aversion causes the endowment effect," Journal of Experimental Social Psychology, 45, 947-951. 
Odean, Terrance (1999): "Do Investors Trade too Much?” American Economic Review, 89, 1279-1298.

Payne, John W., Dan, J. Laughhunn, and Roy Crum (1980): “Translation of Gambles and Aspiration Level Effects in Risky Choice Behavior,” Management Science, 26, 10391060.

Payne, John W., Dan J. Laughhunn, and Roy Crum (1981): "Further Tests of Aspiration Level Effects in Risky Choice Behavior,” Management Science, 27, 953-958.

Payne, John W., James R. Bettman, and Eric J. Johnson (1993): The Adaptive Decision Maker, (Cambridge: Cambridge University Press).

Pesendorfer, Wolfgang (2006): "Behavioral Economics Comes of Age: A Review Essay on Advances in Behavioral Economics,” Journal of Economic Literature, 44, 712-721.

Pocheptsova, Anastasiya, On Amir, Ravi Dhar and Roy F. Baumeister (2009): "Deciding without Resources: Resource Depletion and Choice in Context," Journal of Marketing Research, 46, 344-355.

Polkovnichenko, Valery (2005): "Household Portfolio Diversification: A Case for RankDependent Preferences, Review of Financial Studies, 18, 1467-1502.

Plott, Charles R., and Kathryn Zeiler (2005): “The Willingness to Pay - Willingness to Accept Gap, the "Endowment Effect," Subject Misconceptions, and Experimental Procedures for Eliciting Valuations," American Economic Review, 95, 530-545.

Plott, Charles R., and Kathryn Zeiler (2007): "Exchange Asymmetries Incorrectly Interpreted as Evidence of Endowment Effect Theory and Prospect Theory?" American Economic Review, 97, 1449-1466.

Redelmeier, Donald A., and Amos Tversky (1992): "On the framing of multiple prospects," Psychological Science, 3, 191-193.

Rietz, Thomas A. (1988): “The Equity Risk Premium: A Solution,” Journal of Monetary Economics, 22, 117-31.

Ritov, Ilana and Jonathan Baron (1992): “Status Quo and Omission Biases,” Journal of Risk and Uncertainty, 5, 49-61.

Samuelson, Larry (2005): “Economic Theory and Experimental Economics,” Journal of Economic Literature, 43, 65-107.

Samuelson, Paul A. (1963): "Risk and Uncertainty: A Fallacy of Large Numbers," Scientia, 98, 108-113.

Samuelson, William, and Richard Zeckhauser (1988): "Status quo Bias in Decision Making," Journal of Risk and Uncertainty, 1, 7-59. 
Schmidt, Ulrich, and Stefan Traub (2002): “An Experimental Test of Loss Aversion,” Journal of Risk and Uncertainty, 25, 233-249.

Schmeichel, Brandon. J. (2007): “Attention Control, Memory Updating, and Emotion Regulation Temporarily Reduce the Capacity for Executive Control," Journal of Experimental Psychology: General, 136, 241-55.

Schmidt, Ulrich, and Horst Zank (2005): "What is Loss Aversion?" Journal of Risk and Uncertainty, 30, 157-167.

Schoemaker, Paul J. H. (1990): “Are Risk-Attitudes Related Across Domains and Response Modes?” Management Science, 36, 1451-1463.

Thaler, Richard H., and Eric J. Johnson (1990): "Gambling with the House Money and Trying to Break Even: The Effects of Prior Outcomes on Risky Choice," Management Science, $36,643-660$.

Thaler, Richard H., Amos Tversky, Daniel Kahneman, and Alan Swartz (1997): “The Effect of Myopia and Loss Aversion on Risk Taking: An Experimental Test," Quarterly Journal of Economics, 112, 647-661.

Tom, Sabrina M., Craig R. Fox, Christopher Trepel, and Russel A. Poldrack (2007): “The neural basis of loss aversion in decision making under risk." Science, 315, 515-518.

Tversky, Amos and Daniel Kahneman (1991): “Loss Aversion in Riskless Choice," Quarterly Journal of Economics, 106, 1039-1061.

Tversky, Amos and Daniel Kahneman (1992): “Advances in prospect theory: Cumulative representation of uncertainty." Journal of Risk and Uncertainty, 5, 297-323.

Viscusi, Kip, W., Wesley A. Magat, and Joel Huber (1987): “An investigation of the rationality of consumer valuations of multiple health risks," RAND Journal of Economics, $18,465-479$.

Vohs, Kathleen D., Roy F. Baumesiter, Brandon J. Schmeichel, Jean M. Twenge, Noelle M. Nelson, and Dianne M. Tice (2008) "Making Choices Impairs Subsequent Self-Control: A Limited-Resource Account of Decision Making, Self-Regulation, and Active Initiative," Journal of Personality and Social Psychology, 94, 883-898.

Wakker, Peter P. (2009) Prospect Theory for Risk and Ambiguity, (Cambridge University Press: Cambridge, UK).

Williams, Arthur C. (1966): “Attitudes Toward Speculative Risks as an Indicator of Attitudes Toward Pure Risks,” Journal of Risk and Insurance, 33, 577-586.

Wu, George, and Alex B. Markle (2008): “An Empirical Test of Gain-Loss Separability in Prospect Theory," Management Science, 54, 1322-1335. 


\section{Appendix A. The Cumulative Prospect Theory Model (CPT).}

According to cumulative prospect theory (Tversky and Kahneman 1992), decision-makers are assumed to select the prospect with the highest weighted value. The weighted value of Prospect $\mathrm{X}$ that pays $\mathrm{x}_{1}$ with probability $\mathrm{p}_{1}$, and $\mathrm{x}_{2}$ otherwise (probability $\mathrm{p}_{2}=1-\mathrm{p}_{1}$ ) is:

(1) $W V(X)=V\left(x_{1}\right) \pi\left(p_{1}\right)+V\left(x_{2}\right) \pi\left(p_{2}\right)$

where $\mathrm{V}\left(\mathrm{x}_{\mathrm{i}}\right)$ is the subjective value of outcome $\mathrm{x}_{\mathrm{i}}$, and $\pi\left(\mathrm{p}_{\mathrm{i}}\right)$ is the subjective weight of outcome $\mathrm{x}_{\mathrm{i}}$. The subjective values are given by a value function that can be described as follows:

$$
V\left(x_{i}\right)=\left\{\begin{array}{c}
x_{i}^{\alpha} \quad \text { if } \quad x_{i} \geq 0 \\
-\lambda\left|x_{i}\right|^{\beta} \quad \text { if } \quad x_{i}<0
\end{array}\right.
$$

The parameters $0<\alpha<1$ and $0<\beta<1$ reflect diminishing sensitivity to increases in the absolute payoffs in the gain and the loss domain respectively. According to the diminishing sensitivity assumption, the subjective impact of a change in the absolute payoff decreases with the distance from zero. The parameter $\lambda>1$ captures the loss aversion assertion, suggesting that losses loom larger than equivalent gains.

The subjective weights are assumed to depend on the outcomes' rank and sign, and on a cumulative weighting function. When the two outcomes are of different signs, the weight of outcome $i$ is:

$$
\pi\left(p_{i}\right)=\left\{\begin{array}{lll}
\frac{p_{i}^{\gamma}}{\left(p_{i}^{\gamma}+\left(1-p_{i}\right)^{\gamma}\right)^{1 / \gamma}} & \text { if } \quad x_{i} \geq 0 \\
\frac{p_{i}^{\delta}}{\left(p_{i}^{\delta}+\left(1-p_{i}\right)^{\delta}\right)^{1 / \delta}} & \text { if } & x_{i}<0
\end{array}\right.
$$

The parameters $0<\gamma<1$ and $0<\delta<1$ capture the tendency to overweight low-probability extreme outcomes.

When the outcomes are of the same sign, the weight of the most extreme outcome (largest absolute value) is computed with equation (3) (as if it is the sole outcome of that sign), and the weight of the less extreme outcome is the difference between that value and 1 . 
The five parameters of the CPT model were estimated, using a grid search method with a mean squared deviation criteria, to simultaneously fit the experimental problems of each study separately. The best fitted parameters for each of those studies are the following.

A.1 CPT parameters, fitted on the data of study 3:

$\alpha=.5, \beta=.45, \gamma=0.70, \delta=0.84, \lambda=1.6(\mathrm{MSD}=.16693)$.

A.2 CPT parameters, fitted on the data of study 4 :

$\alpha=.5, \beta=.5, \gamma=1, \delta=1, \lambda=1(\mathrm{MSD}=.05379)$.

A.3 CPT parameters, fitted on the data of study 5:

$\alpha=0.6, \beta=0.6, \gamma=0.8, \delta=0.8, \lambda=1(\mathrm{MSD}=.08230)$. 


\section{TABLE I}

SUMMARY OF NINE PREVIOUS STUDIES OF LOSS AVERSION UNDER RISK

\begin{tabular}{|c|c|c|}
\hline Study & $\begin{array}{l}\text { \# of } \\
\text { choice } \\
\text { problems } \\
\text { faced by } \\
\text { each } \\
\text { participant }\end{array}$ & $\begin{array}{l}\text { Choice rate of the } \\
\text { prospect } \\
\text { associated with } \\
\text { larger variance } \\
\text { over problems } \\
\text { (and in the } \\
\text { example) }\end{array}$ \\
\hline $\begin{array}{l}\text { Study 2. Real payoffs for randomly selected choice in Sheqels. } \\
\text { Example: }(10 ; .5-10) \text { or }(20, .5 ;-20)\end{array}$ & 2 & $\begin{array}{l}58 \% \\
(58 \%)\end{array}$ \\
\hline $\begin{array}{l}\text { Study 1. Hypothetical payoffs in Sheqels. } \\
\text { Example: (0) or }(1000, .5 ;-1000)\end{array}$ & 4 & $\begin{array}{l}44 \% \\
(50 \%)\end{array}$ \\
\hline $\begin{array}{l}\text { Ert and Yechiam (2009). Hypothetical payoffs in Sheqels. } \\
\text { Example: (0) or }(100, .5 ;-100)\end{array}$ & 8 & $\begin{array}{l}55 \% \\
(66 \%)\end{array}$ \\
\hline $\begin{array}{l}\text { Thaler and Johnson (1990). Real payoffs for randomly selected } \\
\text { participants in US dollars. } \\
\text { Example: (0) or }(2.5, .5 ;-2.5)\end{array}$ & 8 & $\begin{array}{l}54 \% \\
(50 \%)\end{array}$ \\
\hline $\begin{array}{l}\text { Battalio et al. (1990). Real payoffs for randomly selected choice in } \\
\text { US Dollars. } \\
\text { Example: }(0) \text { or }(10, .5 ;-10)\end{array}$ & 15 & $\begin{array}{l}51 \% \\
(60 \%)\end{array}$ \\
\hline $\begin{array}{l}\text { Wu and Markle (2008). Hypothetical payoffs in US dollars. } \\
\text { Example: }(1000, .3 ;-200) \text { or }(400, .7 ;-500)\end{array}$ & 20 & $\begin{array}{l}50 \% \\
(51 \%)\end{array}$ \\
\hline $\begin{array}{l}\text { Erev et al. (2010). Estimation set. Real payoffs for randomly } \\
\text { selected choice in Sheqels. } \\
\text { Example: }(5.6) \text { or }(7.3, .8 ;-3.6)\end{array}$ & 60 & $\begin{array}{l}39 \% \\
(15 \%)\end{array}$ \\
\hline $\begin{array}{l}\text { Erev et al. (2010). Competition set. Real payoffs for randomly } \\
\text { selected choice in Sheqels. } \\
\text { Example: }(2.7) \text { or }(3.3, .91 ;-3.5)\end{array}$ & 60 & $\begin{array}{l}36 \% \\
(25 \%)\end{array}$ \\
\hline $\begin{array}{l}\text { Brooks and Zank (2005). Real payoffs for randomly selected choice } \\
\text { in British pounds. } \\
\text { Example: }(4, .33 ; 0, .33 ;-4) \text { or }(5, .33 ; 0, .33 ;-5)\end{array}$ & 96 & $\begin{array}{l}37 \% \\
(35 \%)\end{array}$ \\
\hline
\end{tabular}

Note: The results reveal that the proportion of choices consistent with loss aversion increases with the number of problems faced by each participant. 
TABLE II

The 90 MiXed Problems EVAluATEd IN StUdy 3

Prob

\begin{tabular}{|c|c|c|c|c|c|c|c|c|c|c|c|c|c|c|c|}
\hline oblem & S1 & Ps & S2 & R1 & $\mathrm{Pr}$ & $\mathrm{R} 2$ & $P$ (risk) & Problem & S1 & Ps & $\mathrm{S} 2$ & $\mathrm{R} 1$ & $\mathrm{Pr}$ & $\mathrm{R} 2$ & $P$ (risk) \\
\hline 1 & 7 & 0.38 & -6 & 16 & 0.47 & -16 & 0.57 & 46 & 8 & 0.46 & -9 & 15 & 0.46 & -15 & 0.40 \\
\hline 2 & 9 & 0.57 & -2 & 10 & 0.80 & -18 & 0.37 & 47 & 3 & 0.51 & -8 & 11 & 0.46 & -14 & 0.37 \\
\hline 3 & 10 & 0.49 & -7 & 16 & 0.54 & -16 & 0.43 & 48 & 6 & 0.52 & -7 & 12 & 0.55 & -15 & 0.50 \\
\hline 4 & 10 & 0.50 & -4 & 13 & 0.57 & -10 & 0.50 & 49 & 10 & 0.46 & -5 & 19 & 0.51 & -16 & 0.50 \\
\hline 5 & 8 & 0.50 & -10 & 11 & 0.45 & -11 & 0.53 & 50 & 7 & 0.49 & -10 & 16 & 0.37 & -12 & 0.23 \\
\hline 6 & 8 & 0.51 & -3 & 14 & 0.64 & -18 & 0.50 & 51 & 10 & 0.39 & -1 & 14 & 0.59 & -12 & 0.40 \\
\hline 7 & 1 & 0.57 & -6 & 15 & 0.50 & -19 & 0.30 & 52 & 6 & 0.55 & -3 & 17 & 0.58 & -19 & 0.43 \\
\hline 8 & 4 & 0.47 & -2 & 13 & 0.57 & -15 & 0.43 & 53 & 9 & 0.52 & -3 & 11 & 0.66 & -12 & 0.57 \\
\hline 9 & 8 & 0.53 & -9 & 17 & 0.39 & -11 & 0.30 & 54 & 9 & 0.47 & -6 & 13 & 0.61 & -18 & 0.63 \\
\hline 10 & 3 & 0.38 & -10 & 10 & 0.44 & -17 & 0.77 & 55 & 4 & 0.54 & -5 & 19 & 0.40 & -13 & 0.20 \\
\hline 11 & 11 & 0.36 & -11 & 15 & 0.40 & -15 & 0.60 & 56 & 2 & 0.54 & -3 & 16 & 0.52 & -18 & 0.30 \\
\hline 12 & 11 & 0.41 & -10 & 18 & 0.33 & -11 & 0.37 & 57 & 10 & 0.53 & -9 & 17 & 0.45 & -12 & 0.40 \\
\hline 13 & 4 & 0.37 & -8 & 18 & 0.37 & -16 & 0.40 & 58 & 1 & 0.56 & -9 & 17 & 0.24 & -10 & 0.43 \\
\hline 14 & 8 & 0.57 & -7 & 18 & 0.54 & -18 & 0.23 & 59 & 4 & 0.59 & -5 & 17 & 0.44 & -13 & 0.23 \\
\hline 15 & 10 & 0.37 & -6 & 14 & 0.51 & -15 & 0.57 & 60 & 11 & 0.36 & -5 & 15 & 0.43 & -10 & 0.57 \\
\hline 16 & 7 & 0.36 & -4 & 14 & 0.55 & -17 & 0.40 & 61 & 7 & 0.36 & -4 & 19 & 0.47 & -17 & 0.53 \\
\hline 17 & 3 & 0.62 & -4 & 14 & 0.56 & -17 & 0.33 & 62 & 11 & 0.49 & -2 & 16 & 0.64 & -16 & 0.37 \\
\hline 18 & 8 & 0.56 & -5 & 18 & 0.54 & -16 & 0.17 & 6 & 1 & 0.50 & -1 & 14 & 0.44 & -11 & 0.40 \\
\hline 19 & 8 & 0.40 & -2 & 14 & 0.56 & -13 & 0.53 & 64 & 4 & 0.38 & -6 & 15 & 0.43 & -15 & 0.50 \\
\hline 20 & 6 & 0.55 & -5 & 12 & 0.50 & -10 & 0.20 & 65 & 6 & 0.42 & -10 & 13 & 0.47 & -18 & 0.50 \\
\hline 21 & 3 & 0.65 & -5 & 11 & 0.60 & -16 & 0.23 & 66 & 7 & 0.39 & -10 & 12 & 0.33 & -11 & 0.53 \\
\hline 22 & 6 & 0.59 & -6 & 16 & 0.56 & -18 & 0.20 & 67 & 11 & 0.57 & -6 & 17 & 0.60 & -16 & 0.33 \\
\hline 23 & 6 & 0.40 & -10 & 12 & 0.42 & -15 & 0.73 & 60 & 6 & 0.38 & -4 & 17 & 0.43 & -13 & 0.57 \\
\hline 24 & 10 & 0.63 & -2 & 13 & 0.70 & -12 & 0.20 & 69 & 6 & 0.57 & -11 & 18 & 0.36 & -12 & 0.27 \\
\hline 25 & 7 & 0.40 & -11 & 15 & 0.41 & -17 & 0.43 & 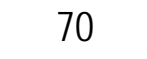 & 2 & 0.40 & -4 & 14 & 0.44 & -14 & 0.43 \\
\hline 26 & 3 & 0.45 & -7 & 18 & 0.29 & -11 & 0.20 & 71 & 6 & 0.41 & -10 & 15 & 0.34 & -13 & 0.43 \\
\hline 27 & 4 & 0.47 & -6 & 15 & 0.44 & -14 & 0.27 & 72 & 11 & 0.57 & -11 & 19 & 0.54 & -19 & 0.10 \\
\hline 28 & 9 & 0.50 & -2 & 16 & 0.57 & -13 & 0.40 & 73 & 8 & 0.46 & -4 & 14 & 0.62 & -19 & 0.57 \\
\hline 29 & 7 & 0.67 & -10 & 18 & 0.53 & -17 & 0.23 & 74 & 7 & 0.56 & -8 & 13 & 0.52 & -13 & 0.43 \\
\hline 30 & 2 & 0.41 & -10 & 17 & 0.31 & -15 & 0.47 & 75 & 7 & 0.65 & -11 & 12 & 0.64 & -19 & 0.27 \\
\hline 31 & 9 & 0.66 & -9 & 11 & 0.66 & -13 & 0.47 & 76 & 2 & 0.65 & -10 & 17 & 0.42 & -16 & 0.37 \\
\hline 32 & 2 & 0.60 & -10 & 13 & 0.49 & -18 & 0.43 & 77 & 4 & 0.36 & -9 & 17 & 0.24 & -11 & 0.47 \\
\hline 33 & 2 & 0.45 & -6 & 16 & 0.41 & -15 & 0.47 & 78 & 3 & 0.58 & -6 & 16 & 0.51 & -18 & 0.43 \\
\hline 34 & 9 & 0.41 & -4 & 19 & 0.46 & -14 & 0.43 & 79 & 6 & 0.41 & -5 & 17 & 0.42 & -13 & 0.40 \\
\hline 35 & 10 & 0.42 & -10 & 13 & 0.39 & -11 & 0.43 & 80 & 6 & 0.34 & -5 & 11 & 0.55 & -16 & 0.53 \\
\hline 36 & 8 & 0.43 & -8 & 18 & 0.44 & -16 & 0.47 & 81 & 4 & 0.47 & -8 & 15 & 0.47 & -18 & 0.40 \\
\hline 37 & 8 & 0.65 & -1 & 14 & 0.65 & -12 & 0.13 & 82 & 8 & 0.50 & -7 & 14 & 0.56 & -17 & 0.47 \\
\hline 38 & 9 & 0.61 & -5 & 14 & 0.58 & -11 & 0.30 & 83 & 7 & 0.64 & -10 & 15 & 0.46 & -11 & 0.27 \\
\hline 39 & 4 & 0.65 & -3 & 17 & 0.43 & -10 & 0.27 & 84 & 11 & 0.61 & -1 & 12 & 0.81 & -18 & 0.57 \\
\hline 40 & 1 & 0.63 & -9 & 14 & 0.44 & -16 & 0.40 & 85 & 4 & 0.51 & -9 & 18 & 0.40 & -16 & 0.23 \\
\hline 41 & 1 & 0.49 & -8 & 16 & 0.35 & -14 & 0.30 & 86 & 3 & 0.47 & -3 & 19 & 0.34 & -10 & 0.20 \\
\hline 42 & 5 & 0.54 & -10 & 11 & 0.41 & -11 & 0.47 & 87 & 2 & 0.50 & -7 & 14 & 0.47 & -17 & 0.53 \\
\hline
\end{tabular}


$\begin{array}{llllllllllllllll}43 & 6 & 0.37 & -4 & 12 & 0.47 & -11 & 0.50 & 88 & 9 & 0.60 & -8 & 12 & 0.67 & -18 & 0.57\end{array}$

$\begin{array}{llllllllllllllll}44 & 5 & 0.56 & -7 & 14 & 0.45 & -12 & 0.33 & 89 & 9 & 0.60 & -9 & 10 & 0.71 & -18 & 0.63\end{array}$

$\begin{array}{llllllllllllllll}45 & 11 & 0.55 & -8 & 14 & 0.59 & -14 & 0.63 & 90 & 3 & 0.55 & -8 & 14 & 0.49 & -17 & 0.33\end{array}$

Mean P(risk) Across Problems: 0.41

Note: Each problem involved a choice between a safer prospect (S1, Ps; S2) and a riskier (higher variability) prospect (R1, Pr; R2). The column P(risk) represents the proportion of choices in the riskier prospect $(\mathrm{R})$ in each of those problems. 
TABLE III

The SyMmetric SET OF 90 Problems EVAlUATED IN STUDy 4

\begin{tabular}{|c|c|c|c|c|c|c|c|c|c|c|c|c|c|c|c|}
\hline Problem & S1 & Ps & S2 & R1 & $\mathrm{Pr}$ & R2 & P(risk) & Problem & S1 & Ps & S2 & R1 & $\mathrm{Pr}$ & R2 & $P$ (risk) \\
\hline 1 & 7 & 0.5 & -8 & 11 & 0.5 & -11 & 0.77 & 46 & 7 & 0.5 & -7 & 9 & 0.5 & -9 & 0.45 \\
\hline 2 & 6 & 0.5 & -6 & 13 & 0.5 & -16 & 0.00 & 47 & 5 & 0.5 & -5 & 8 & 0.5 & -8 & 0.50 \\
\hline $3^{\star}$ & 12 & 0.5 & -12 & 11 & 0.5 & -14 & 0.09 & 48 & 9 & 0.5 & -9 & 12 & 0.5 & -12 & 0.41 \\
\hline 4 & 4 & 0.5 & -6 & 13 & 0.5 & -13 & 0.73 & 49 & 6 & 0.5 & -6 & 10 & 0.5 & -10 & 0.59 \\
\hline 5 & 11 & 0.5 & -11 & 12 & 0.5 & -13 & 0.05 & 50 & 4 & 0.5 & -4 & 11 & 0.5 & -11 & 0.50 \\
\hline 6 & 7 & 0.5 & -7 & 9 & 0.5 & -10 & 0.14 & 51 & 5 & 0.5 & -5 & 12 & 0.5 & -11 & 0.64 \\
\hline 7 & 4 & 0.5 & -4 & 9 & 0.5 & -12 & 0.09 & 52 & 4 & 0.5 & -4 & 7 & 0.5 & -6 & 0.68 \\
\hline 8 & 5 & 0.5 & -5 & 7 & 0.5 & -8 & 0.05 & 53 & 11 & 0.5 & -9 & 12 & 0.5 & -11 & 0.27 \\
\hline 9 & 5 & 0.5 & -5 & 12 & 0.5 & -14 & 0.00 & 54 & 5 & 0.5 & -2 & 6 & 0.5 & -6 & 0.05 \\
\hline 10 & 7 & 0.5 & -7 & 8 & 0.5 & -11 & 0.05 & 55 & 8 & 0.5 & -5 & 13 & 0.5 & -13 & 0.18 \\
\hline 11 & 9 & 0.5 & -9 & 11 & 0.5 & -12 & 0.18 & 56 & 10 & 0.5 & -10 & 13 & 0.5 & -12 & 0.64 \\
\hline $12^{\star}$ & 10 & 0.5 & -13 & 12 & 0.5 & -12 & 0.91 & 57 & 8 & 0.5 & -7 & 11 & 0.5 & -11 & 0.32 \\
\hline 13 & 5 & 0.5 & -6 & 9 & 0.5 & -9 & 0.77 & 58 & 12 & 0.5 & -9 & 13 & 0.5 & -13 & 0.18 \\
\hline 14 & 8 & 0.5 & -8 & 12 & 0.5 & -15 & 0.18 & $59 *$ & 7 & 0.5 & -5 & 6 & 0.5 & -6 & 0.05 \\
\hline 15 & 9 & 0.5 & -10 & 11 & 0.5 & -11 & 0.82 & 60 & 6 & 0.5 & -6 & 12 & 0.5 & -11 & 0.59 \\
\hline 16 & 5 & 0.5 & -8 & 13 & 0.5 & -13 & 0.73 & 61 & 4 & 0.5 & -4 & 6 & 0.5 & -5 & 0.91 \\
\hline 17 & 7 & 0.5 & -7 & 10 & 0.5 & -11 & 0.09 & 62 & 6 & 0.5 & -6 & 10 & 0.5 & -9 & 0.68 \\
\hline 18 & 8 & 0.5 & -9 & 10 & 0.5 & -10 & 0.86 & 63 & 6 & 0.5 & -3 & 8 & 0.5 & -8 & 0.14 \\
\hline 19 & 10 & 0.5 & -10 & 12 & 0.5 & -14 & 0.05 & 64 & 4 & 0.5 & -1 & 5 & 0.5 & -5 & 0.00 \\
\hline 20 & 11 & 0.5 & -11 & 14 & 0.5 & -13 & 0.73 & 65 & 8 & 0.5 & -8 & 12 & 0.5 & -9 & 0.86 \\
\hline 21 & 4 & 0.5 & -4 & 6 & 0.5 & -7 & 0.05 & 66 & 8 & 0.5 & -6 & 12 & 0.5 & -12 & 0.27 \\
\hline 22 & 9 & 0.5 & -9 & 11 & 0.5 & -10 & 0.86 & 67 & 5 & 0.5 & -5 & 12 & 0.5 & -10 & 0.73 \\
\hline 23 & 11 & 0.5 & -11 & 13 & 0.5 & -12 & 0.91 & 68 & 6 & 0.5 & -6 & 13 & 0.5 & -11 & 0.59 \\
\hline 24 & 6 & 0.5 & -9 & 12 & 0.5 & -12 & 0.73 & 69 & 6 & 0.5 & -6 & 11 & 0.5 & -9 & 0.77 \\
\hline 25 & 7 & 0.5 & -7 & 8 & 0.5 & -11 & 0.05 & 70 & 8 & 0.5 & -8 & 11 & 0.5 & -10 & 0.59 \\
\hline 26 & 6 & 0.5 & -8 & 11 & 0.5 & -11 & 0.82 & 71 & 11 & 0.5 & -8 & 12 & 0.5 & -12 & 0.09 \\
\hline 27 & 11 & 0.5 & -11 & 12 & 0.5 & -13 & 0.1 & 12 & 10 & 0.5 & -10 & 13 & 0.5 & -11 & 0.82 \\
\hline 28 & 5 & 0.5 & -6 & 11 & 0.5 & -11 & 0.64 & 73 & 8 & 0.5 & -8 & 10 & 0.5 & -9 & 0.86 \\
\hline 29 & 5 & 0.5 & -7 & 0 & 0.5 & -8 & 0.91 & 74 & 7 & 0.5 & -6 & 8 & 0.5 & -8 & 0.27 \\
\hline 30 & 4 & 0.5 & -4 & 5 & 0.5 & -6 & 0.14 & 75 & 6 & 0.5 & -4 & 10 & 0.5 & -10 & 0.18 \\
\hline 31 & 6 & 0.5 & -7 & 12 & 0.5 & -12 & 0.77 & 76 & 11 & 0.5 & -10 & 13 & 0.5 & -13 & 0.27 \\
\hline 32 & 10 & 0.5 & -10 & 11 & 0.5 & -12 & 0.05 & 77 & 4 & 0.5 & -3 & 5 & 0.5 & -5 & 0.23 \\
\hline 33 & 6 & 0.5 & -6 & 7 & 0.5 & -8 & 0.05 & 78 & 5 & 0.5 & -5 & 10 & 0.5 & -8 & 0.68 \\
\hline 34 & 9 & 0.5 & -9 & 13 & 0.5 & -14 & 0.18 & 79 & 9 & 0.5 & -9 & 11 & 0.5 & -10 & 0.86 \\
\hline 35 & 4 & 0.5 & -6 & 9 & 0.5 & -9 & 0.82 & 80 & 9 & 0.5 & -9 & 12 & 0.5 & -10 & 0.82 \\
\hline 36 & 4 & 0.5 & -5 & $y$ & 0.5 & -9 & 0.86 & 81 & 0 & 0.5 & -6 & 9 & 0.5 & -7 & 0.86 \\
\hline 37 & 6 & 0.5 & -6 & 8 & 0.5 & -9 & 0.09 & 82 & 9 & 0.5 & -9 & 11 & 0.5 & -10 & 0.73 \\
\hline 38 & 4 & 0.5 & -7 & 13 & 0.5 & -13 & 0.86 & 83 & 7 & 0.5 & -6 & 13 & 0.5 & -13 & 0.23 \\
\hline 39 & 2 & 0.5 & -3 & 9 & 0.5 & -9 & 0.68 & 84 & 8 & 0.5 & -8 & 12 & 0.5 & -10 & 0.68 \\
\hline 40 & 4 & 0.5 & -4 & 6 & 0.5 & -7 & 0.05 & 85 & 7 & 0.5 & -7 & 10 & 0.5 & -8 & 0.86 \\
\hline 41 & 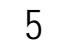 & 0.5 & -5 & 11 & 0.5 & -11 & 0.45 & 86 & 5 & 0.5 & -5 & 11 & 0.5 & -10 & 0.68 \\
\hline
\end{tabular}


$\begin{array}{llllllllllllllll}42 & 1 & 0.5 & -1 & 10 & 0.5 & -10 & 0.45 & 87 & 5 & 0.5 & -5 & 10 & 0.5 & -7 & 0.86\end{array}$

$\begin{array}{llllllllllllllll}43 & 5 & 0.5 & -5 & 6 & 0.5 & -6 & 0.73 & 88 & 4 & 0.5 & -3 & 8 & 0.5 & -8 & 0.18\end{array}$

$\begin{array}{llllllllllllllll}44 & 4 & 0.5 & -4 & 5 & 0.5 & -5 & 0.55 & 89 & 4 & 0.5 & -4 & 7 & 0.5 & -5 & 0.91\end{array}$

$\begin{array}{llllllllllllllll}45 & 4 & 0.5 & -4 & 7 & 0.5 & -7 & 0.50 & 90 & 9 & 0.5 & -8 & 10 & 0.5 & -10 & 0.32\end{array}$

Mean of $\mathrm{P}$ (risk) Across Problems without Dominant Strategy: 0.48

Note: Each problem involved a choice between a safer prospect (S1, Ps; S2) and a riskier (higher variability, or in the case of equal variability: larger losses) prospect (R1, Pr; R2). The column $\mathrm{P}$ (risk) presents the proportion of choices in the riskier prospect $(\mathrm{R})$ in each of those problems (*in three problems one of the options dominates the other: $\mathrm{S}$ is the dominant choice in Problems 3 and 59, and R is the dominant choice in Problem 12). 
TABLE IV

THE PROBLEMS STUDIED IN STUDY 5

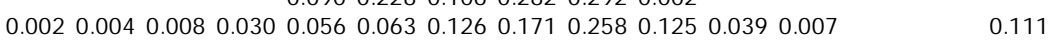

$\begin{array}{lllllllllllllll}0.029 & 0.017 & 0.005 & 0.014 & 0.022 & 0.024 & 0.011 & 0.003 & 0.025 & 0.365 & 0.379 & 0.022 & 0.041 & 0.043\end{array}$

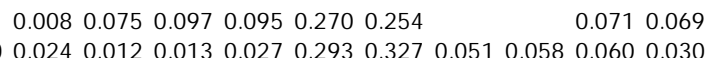
0.0290 .032 $\begin{array}{lllllllll}0.013 & 0.020 & 0.024 & 0.012 & 0.013 & 0.027 & 0.293 & 0.327\end{array}$

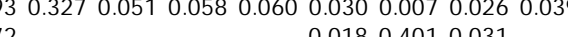
$\begin{array}{llllllllllllllll}0.004 & 0.016 & 0.015 & 0.020 & 0.014 & 0.017 & 0.155 & 0.241 & 0.265 & 0.018 & 0.111 & 0.015 & 0.017 & 0.083 & 0.009\end{array}$ $\begin{array}{lllllllllllllllllllllll}0.003 & 0.018 & 0.056 & 0.119 & 0.161 & 0.117 & 0.158 & 0.114 & 0.129 & 0.005 & 0.064 & 0.031 & 0.025\end{array}$

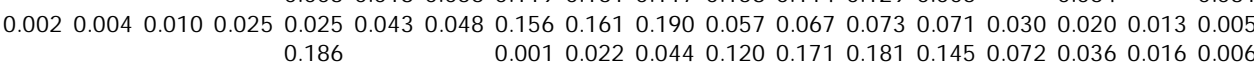
$\begin{array}{llllllllllllllll}0.002 & 0.025 & 0.036 & 0.060 & 0.150 & 0.062 & 0.058 & 0.117 & 0.123 & 0.137 & 0.118 & 0.058 & 0.038 & 0.010 & 0.005 & 0.001\end{array}$ $\begin{array}{lllllllllllll}0.020 & 0.052 & 0.061 & 0.156 & 0.213 & 0.140 & 0.057 & 0.052 & 0.055 & 0.030 & 0.023 & 0.115 & 0.026\end{array}$ 0.086 $\begin{array}{llll}0.019 & 0.698 & 0.283\end{array}$ 0.3930 .372

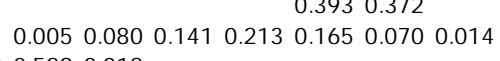
0.0230 .5290 .018 0.0020 .6020 .001 0.0170 .1160 .016 0.395

$\begin{array}{lllllllllll}0.050 & 0.079 & 0.058 & 0.082 & 0.128 & 0.192 & 0.237 & 0.042 & 0.076 & 0.055 & 0.001\end{array}$ $\begin{array}{lllllllllll}0.029 & 0.099 & 0.197 & 0.266 & 0.203 & 0.132 & 0.060 & 0.012 & 0.002\end{array}$

$\begin{array}{lllllllll}0.001 & 0.159 & 0.022 & 0.105 & 0.273 & 0.317 & 0.108 & 0.015\end{array}$ $\begin{array}{llllllllllllll}0.033 & 0.045 & 0.040 & 0.114 & 0.307 & 0.291 & 0.024 & 0.034 & 0.033 & 0.028 & 0.048 & 0.003\end{array}$ $\begin{array}{llllllllll}0.062 & 0.107 & 0.110 & 0.101 & 0.105 & 0.105 & 0.118 & 0.123 & 0.109 & 0.060\end{array}$ $\begin{array}{llll}0.158 & 0.677 & 0.164 & 0.001\end{array}$

$\begin{array}{llllllllll}0.002 & 0.014 & 0.033 & 0.054 & 0.064 & 0.067 & 0.053 & 0.703 & 0.007 & 0.003\end{array}$

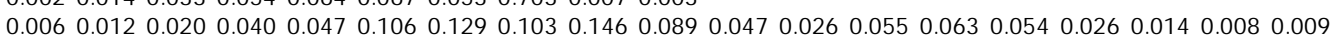

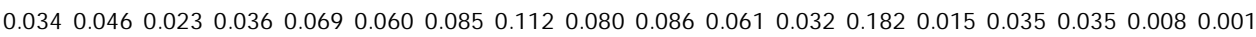
$\begin{array}{lllllllllll}0.005 & 0.049 & 0.105 & 0.192 & 0.188 & 0.154 & 0.108 & 0.045 & 0.005 & 0.149\end{array}$

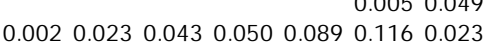
$\begin{array}{lllllllll}0.013 & 0.038 & 0.171 & 0.336 & 0.083 & 0.012 & 0.001\end{array}$

$\begin{array}{lllllllll}0.011 & 0.082 & 0.064 & 0.008 & 0.350 & 0.366 & 0.070 & 0.049\end{array}$

$\begin{array}{lllllllllllllll}0.336 & 0.034 & 0.054 & 0.069 & 0.058 & 0.055 & 0.057 & 0.065 & 0.058 & 0.064 & 0.053 & 0.069 & 0.028\end{array}$ $\begin{array}{lllllllllllllll}0.003 & 0.197 & 0.064 & 0.432 & 0.067 & 0.012 & 0.051 & 0.117 & 0.049 & 0.008\end{array}$

$\begin{array}{llllllllllllllll}0.007 & 0.031 & 0.159 & 0.144 & 0.019 & 0.002 & 0.014 & 0.101 & 0.210 & 0.107 & 0.019 & 0.004 & 0.101 & 0.003 & 0.079\end{array}$ $\begin{array}{lllllllllll}0.033 & 0.093 & 0.137 & 0.147 & 0.179 & 0.156 & 0.160 & 0.065\end{array}$

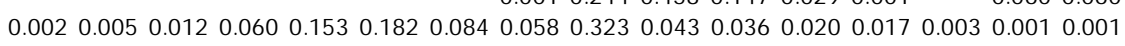
0.0490 .4620 .4300 .059 $\begin{array}{lllllllll}0.033 & 0.169 & 0.022 & 0.016 & 0.379 & 0.358 & 0.023\end{array}$

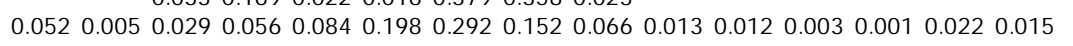


Note: Each problem involved a choice between a safer prospect and a riskier (higher variability) prospect. The two right-most columns $\mathrm{P}$ (risk) represent the proportion of choices in the riskier prospect $(\mathrm{R})$ in the two versions of each problem. 


\section{TABLE V}

LOSS AVERSION AND BEHAVIORAL PHENOMENA

\begin{tabular}{ll}
\hline Examples of phenomena that have been explained with the & Examples of phenomena that appear to \\
loss aversion assertion, and an example of alternative & $\begin{array}{l}\text { reflect risk seeking in choice among mixed } \\
\text { prospects }\end{array}$
\end{tabular}

Status quo bias (Samuelson and Zeckhauser 1988)

Overtrading (Odean 1999)

Alternative explanations:

Individual Trait (Samuelson and Zeckhauser 1988)

Omission bias (Baron and Ritov 1991)

Decision Avoidance (Anderson 2003)

Implicit recommendations (McKenzie et al. 2006)

Inertia (Gal 2006)

Endowment effect (Knetsch and Sinden 1984)

Overbidding and the winner curse (Kagel and Levin 2008; Bazerman and Samuelson

Alternative explanations: 1983)

Asymmetric information (Dupont and Lee 2001)

Mere ownership (Morewedge et al. 2009)

Subject misconceptions (Plott and Zeiler 2005)

Inertia (Gal 2006)

Classical preference theories (Plott and Zeiler 2007)

Underinvestment in stocks Under diversification (Barber and Odean 2000; Polkovnichenko 2005)

Alternative explanations:

Monetary constraints (Constantinides et al. 2002)

Habit persistence (Constantinides 1990)

Impact of rare disastrous events (Rietz 1988)

Incomplete markets (e.g., Aiyagari and Gertler 1991) 


\section{$\mathrm{P}($ risk $)$}

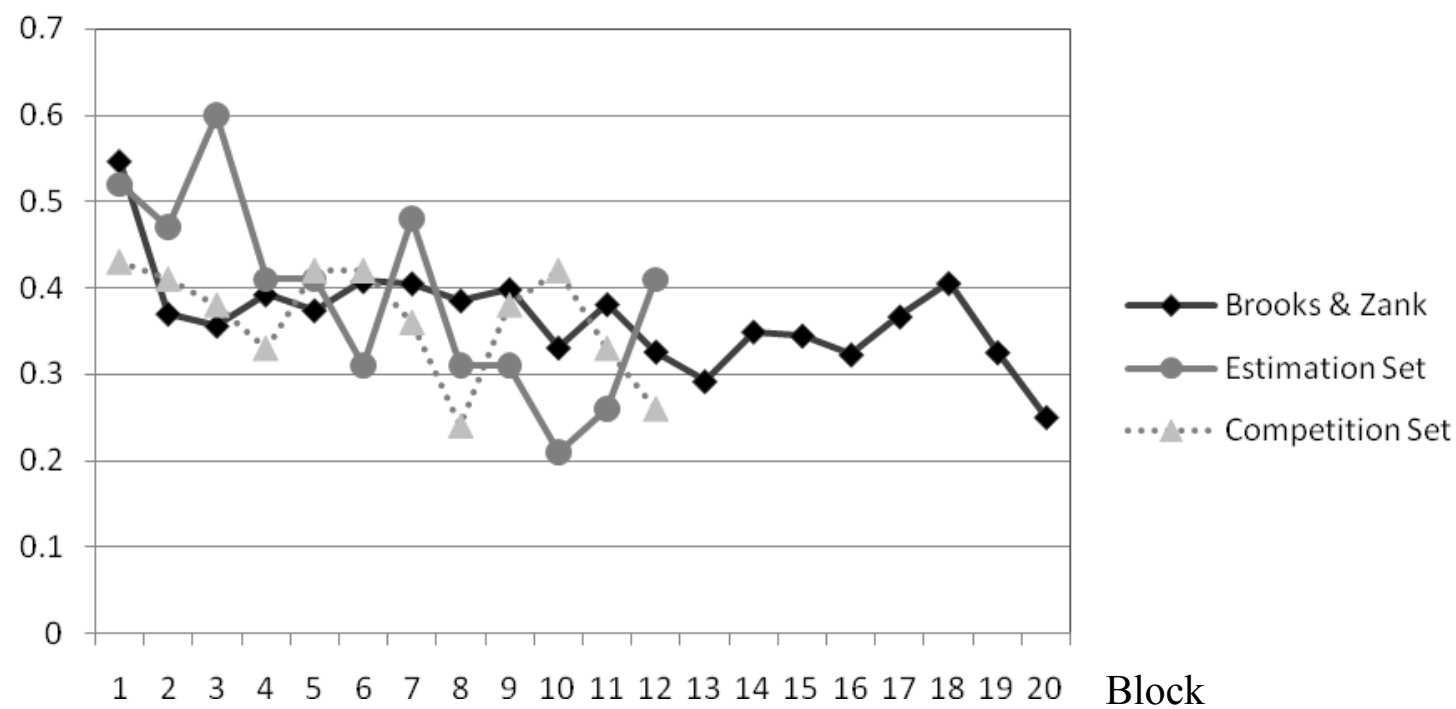

FIGURE 1. Proportion of choices of the riskier mixed gamble over time in three studies The three studies include Brooks and Zank's (2005) study, and the two studies in Erev et al. (2009). The data are summarized in blocks of 5 trials. 


\section{P(risk)}

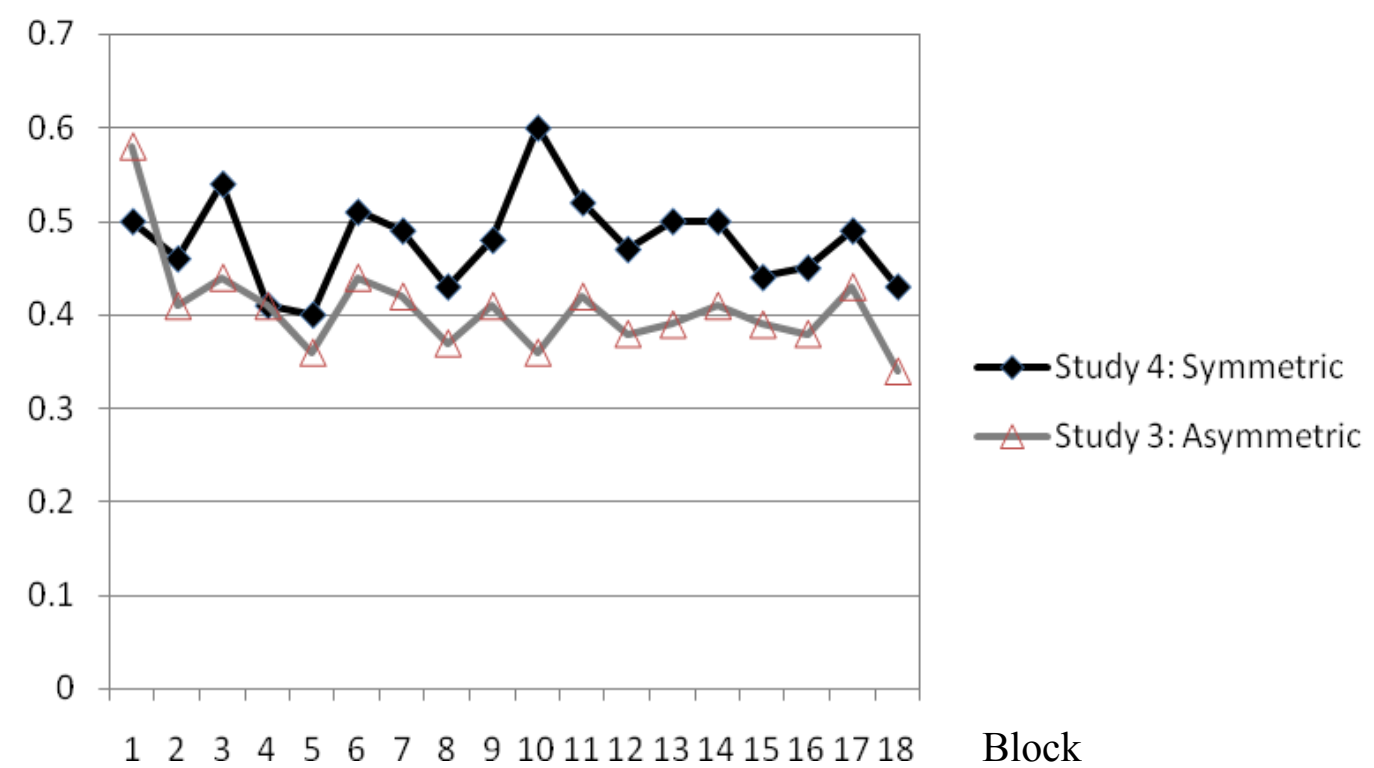

FIGURE 2. Proportion of choices of the riskier mixed gamble over time in Studies 3 and 4. The data are summarized in 18 blocks of 5 problems. 


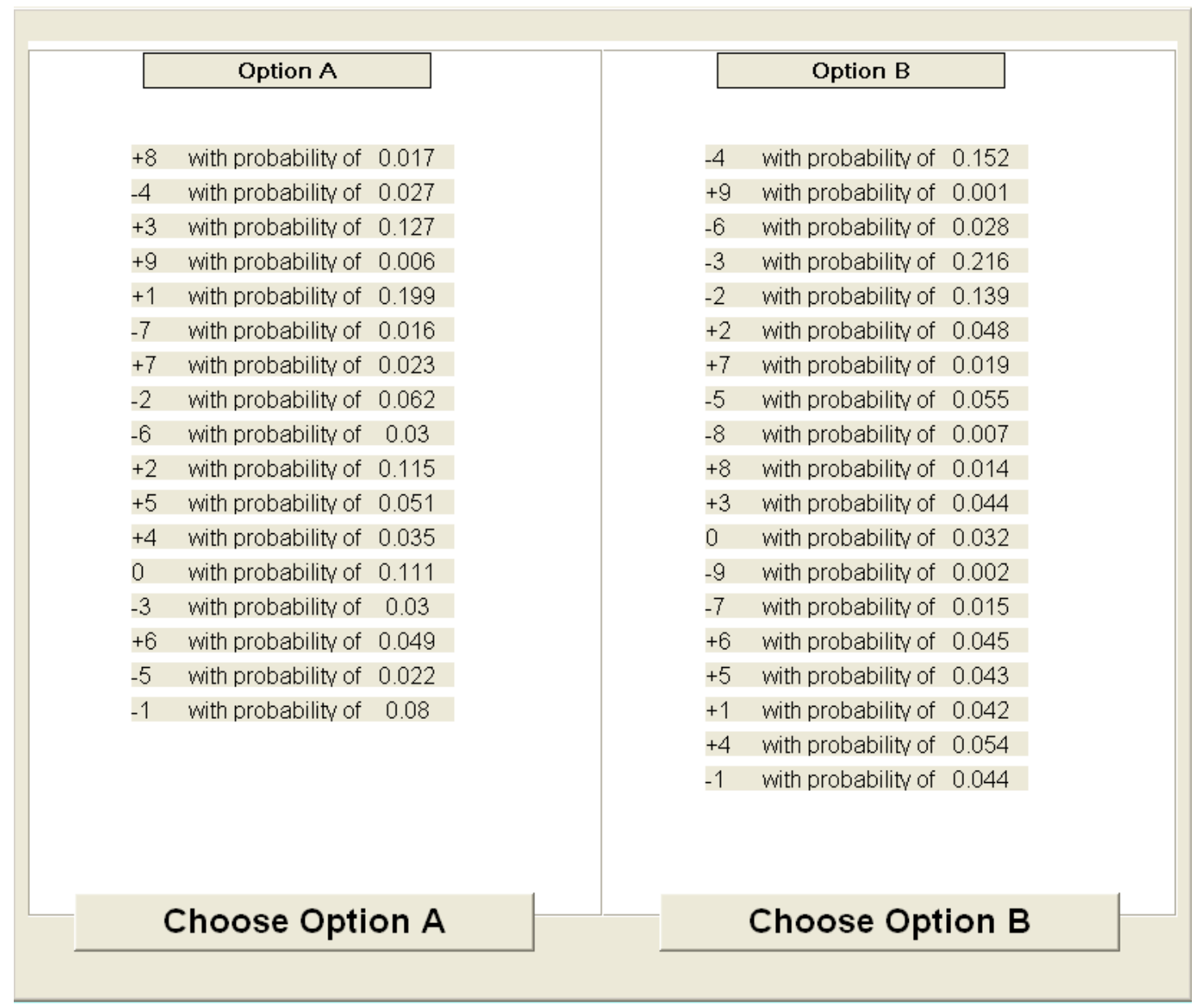

FIGURE 3. An example of the experimental screen in Study 4. 